\title{
Assessment of breast cancer awareness level among Saudi medical students
}

\author{
Abstract \\ Objective: To assess the levels of breast cancer related knowledge among Saudi medical \\ students.
}

Methodology: This is a cross sectional survey conducted in three medical colleges at university of Hail, Kingdom of Saudi Arabia (KSA). About 254 medical students have participated in the survey.

Results: On asking participants about their existing level of knowledge regarding breast cancer, 55/254(21.6\%), 102/254(40\%), 85/254(33.4\%) and 12/254(5\%) of the participants indicated very good, good, poor and know nothing, respectively.

Conclusion: Saudi medical students' level of awareness of breast cancer is very low for several variables, which may be a predictor for the worse among general population.

Keywords: breast cancer, awareness, medical students, Saudi Arabia
Volume 7 Issue 4 - 2017

\author{
Hussain Gadelkarim Ahmed, ${ }^{1,2}$ Ibraheem \\ MAshankyty, ${ }^{3}$ Ali Ghannam Alrashidi,' \\ Kalaf Jaze Kalaf Alshammeri,' Sami Awejan \\ Alrashedi,' Mashail basheir Alshammari,' \\ Nawaf Oudah M Alhazmi,' Mishari Aljarwan' \\ 'College of Medicine, University of Hail, Kingdom of Saudi \\ Arabia \\ ${ }^{2}$ King Khalid Hospital, KSA \\ ${ }^{3}$ Molecular Diagnostics and Personalized Therapeutics Unit, \\ University of $\mathrm{Ha}^{\prime} \mathrm{il}, \mathrm{KSA}$
}

Correspondence: Prof. Hussain Gadelkarim Ahmed; College of Medicine, 2440, University of Hail, KSA, Email hussaingad1972@yahoo.com

Received: December 16, 2016 | Published: February 16, 2017

\section{Introduction}

Breast cancer continues to be a major public health problem worldwide. ${ }^{1}$ There is marked geographical variation in incidence rates, being highest in the developed world and lowest in the developing countries in Asia, Middle East, and Africa. Breast cancer rates are increasing in developed as well as developing countries. ${ }^{2}$ Therefore, it is important that efforts in prevention and early diagnosis of breast cancer are employed everywhere. One of the key difficulties regarding breast cancer relates to the lack of patients' awareness about the disease. ${ }^{3}$ Constraints in employing breast self-examination and mammography screening programs are the key problems. Overall survival and mortality due to this disease are strongly affected by the stage of the disease at diagnosis. Approximately 54\% of women are diagnosed in stage II, while only $16 \%$ diagnosed in stage $\mathrm{I}^{3}$

In the Kingdom of Saudi Arabia (KSA), breast cancer is measured as the commonest malignancy and represents the second leading cause of cancer deaths after lung cancer. ${ }^{5}$ In Saudi Arabia, studies reported insufficient knowledge about breast cancer and its early detection measures which have a negative influence on the practice of breast self-examination among female. ${ }^{6}$ This cancer carries wonderful socioeconomic, emotional, and public health consequences. Breast cancer incidence rates in Arab women have increased during the last 24years, but women are still being diagnosed with Breast Cancer at more advanced stages of the disease. ${ }^{7-10}$ Despite the low cancer incidence in the KSA, the country must be prepared to face the challenge of predictable increase in cancer burden attributed to growth and aging of population. ${ }^{11}$

A number of risk factors that contributed to the etiology of breast cancer have been recognized. ${ }^{12,13}$ These include genetic, reproductive, environmental and socioeconomic risk factors, ${ }^{14}$ obesity, young age at menarche, late age at first child, short period of lactation and being physically inactive. ${ }^{15,16}$ nevertheless, reports from developed countries with high prevalence of recognized risk factors indicated that about $50 \%$ of breast cancer risk is related to these well-known factors. ${ }^{17,18}$ Community educational programs that implement thoroughly Knowledge regarding these risk factors absolutely prevent many cases and render early detection of others. Raise of population awareness toward these risk factors may reduce the burden of breast cancer. Medical students are the most suitable candidates to raise general population awareness. Therefore, the aim of the present study was to assess the levels of breast cancer related knowledge among Saudi medical students.

\section{Materials and methods}

In this is a cross sectional study, data were obtained from 254 Saudi volunteers living in the city of Hail, the Kingdom of Saudi Arabia (KSA) and studying medical colleges (University of Hail) including: College of Medicine and college of Applied Medical Sciences. Participants were randomly selected by simple random regardless to age, gender and education year. Purposeful questionnaire was designed and used for collection of the required data. The following information were obtained from each participant: age, sex, Level of $\mathrm{BC}$ Knowledge, did you care to know about BC, Rate BC in KSA, $\mathrm{BC}$ may affect, $\mathrm{BC}$ may be inherited, rate your Knowledge about $\mathrm{BC}$, did you care to know more about $\mathrm{BC}$ in KSA, Rate the community Knowledge about $\mathrm{BC}$ in KSA, Role of ministry in community awareness, and The best BC treatment.

\section{Data analysis}

Statistical Package for Social Sciences (version 16) was used for analysis and to perform Pearson Chi-square test for statistical significance ( $\mathrm{P}$ value). The 95\% confidence level and confidence intervals were used. $\mathrm{P}$ value less than 0.05 was considered statistically significant

\section{Ethical consent}

Each participant was asked to sign a written ethical consent during the questionnaire's interview. The informed ethical consent form was designed and approved by the ethical committee of the College of Medicine (University of Hail, KSA) Research Board. 


\section{Results}

This study assessed the level of breast cancer awareness of 254 medical students, their ages ranging for 19 to 28years old with a mean age of 22years. Out of the 254 medical students, 132 were males (52\%) and 122 were females (48\%). On asking participants about their existing level of knowledge regarding breast cancer, $55 / 254(21.6 \%), 102 / 254(40 \%), 85 / 254(33.4 \%)$ and $12 / 254(5 \%)$ of the participants indicated very good, good, poor and know nothing, respectively. Out of the 55 participants with very good knowledge about BC, 23/55(41.8\%) were males and 32/55(58.2\%). Out of the 102 participants with good knowledge about BC, 46/102(45\%) were males and $56 / 102(55 \%)$. Out of the 85 participants with poor knowledge about BC, 59/85(69.4\%) were males and $26 / 85(30.6 \%)$. Out of the 12 participants with nothing knowledge about BC, 5/12(41.7\%) were males and 7/12(58.3\%), as indicated in Table 1 \& Figure 1.

Table I Distribution of the study population by general knowledge about breast cancer and its associated factors

\begin{tabular}{|c|c|c|c|c|}
\hline Variable & Category & Males & Females & Total \\
\hline \multicolumn{5}{|c|}{ Level of BC Knowledge } \\
\hline & Very good & 23 & 32 & 55 \\
\hline & Good & 46 & 56 & 102 \\
\hline & Poor & 59 & 26 & 85 \\
\hline & Nothing & 5 & 7 & 12 \\
\hline \multicolumn{5}{|c|}{ Care to know about BC } \\
\hline & Yes & 109 & 108 & 217 \\
\hline & No & 23 & 14 & 37 \\
\hline \multicolumn{5}{|c|}{$B C$ in KSA rated as } \\
\hline & The commonest & 118 & 112 & 230 \\
\hline & Not common & 8 & 2 & 10 \\
\hline & Rare & 6 & 8 & 14 \\
\hline \multicolumn{5}{|c|}{ BC may affect } \\
\hline & Males only & 6 & 5 & 11 \\
\hline & Females only & 30 & 30 & 67 \\
\hline & Both & 86 & 87 & 176 \\
\hline \multicolumn{5}{|c|}{$B C$ may be inherited } \\
\hline & Yes & 15 & 5 & 20 \\
\hline & No & 117 & 117 & 254 \\
\hline
\end{tabular}

On asking them whether one caring to know about breast cancer, $217 / 254(85.4 \%$ ) were found caring to know and $37 / 254(14.6 \%$ ) were found careless. Out of the 37 who were careless to about breast cancer, $23 / 37(62 \%)$ were males and 14/37(38\%) were females. The caring individual's distribution was similar among both genders.

When asking them to rate breast cancer in KSA, 230/254(90.5\%), $10 / 254(4 \%)$ and 14/254(5.5\%), had rated BC in KSA as the commonest, not common, rare, respectively. Out of the 10 participants who described breast cancer as uncommon, 8/10(80\%) were males and $2 / 10(20 \%)$ were females. Out of the 14 participants who described breast cancer as rare, 6/14(42.8\%) were males and 8/14(57.2\%) were females.

On the relationship between $\mathrm{BC}$ and gender, 11/254(4.3\%), $67 / 254(26.4 \%)$ and $176 / 254(69.3 \%)$ had stated that BC affect, males only, females only and both gender, respectively. The distribution of participants was similar in both males and females. On asking them whether BC may be inherited, 20/254(7.8\%) indicated yes and the remaining234/254(92.2\%) indicated no. Out of the 20 participants who indicated yes, $15 / 20(75 \%)$ were males and 5/20(25\%) were females. Out of the 234 participants indicated no, 117/254(50\%) were males and $117 / 254(50 \%)$ were females, as indicated in Table 1 \& Figure 2 .

Table 2 summarizes the distribution of the study population by knowledge of factors related to breast cancer. On asking them to rate their personal knowledge about breast cancer 158 participants have responded of whom 45(18 males and 27 females), 83(37 males and 46 females) and 30(19 males and 11 females), have indicated, very good, good and poor knowledge, respectively, as shown in Figure 3.

Table 2 Distribution of the study population by knowledge of factors related to breast cancer

\begin{tabular}{|c|c|c|c|c|}
\hline Variable & Category & Males & Females & Total \\
\hline \multicolumn{5}{|c|}{ Rate your Knowledge about BC } \\
\hline & Very good & 18 & 27 & 45 \\
\hline & Good & 37 & 46 & 83 \\
\hline & Poor & 19 & 11 & 30 \\
\hline & Nothing & 0 & 0 & 0 \\
\hline \multicolumn{5}{|c|}{ Care to know more about BC in KSA } \\
\hline & Yes & 112 & 109 & 221 \\
\hline & No & 17 & 10 & 27 \\
\hline \multicolumn{5}{|c|}{ Rate community Knowledge about BC in KSA } \\
\hline & high & 25 & 18 & 43 \\
\hline & moderate & 32 & 60 & 92 \\
\hline & low & 67 & 36 & 103 \\
\hline \multicolumn{5}{|c|}{ Role of ministry in community awareness } \\
\hline & high & 34 & 45 & 79 \\
\hline & moderate & 49 & 49 & 98 \\
\hline & low & 10 & 6 & 16 \\
\hline \multicolumn{5}{|c|}{ The best $B C$ treatment } \\
\hline & Surgery & 38 & 16 & 54 \\
\hline & Radiotherapy & 7 & 2 & 9 \\
\hline & Chemotherapy & 7 & 3 & 10 \\
\hline & Biological & 2 & 72 & 74 \\
\hline & Alternative Medicine & 2 & 4 & 6 \\
\hline & Psychological & 2 & 4 & 6 \\
\hline & All therapies & 71 & 20 & 91 \\
\hline
\end{tabular}

On asking them to rate their personal care to knowledge more about breast cancer, 248 have responded of whom 221 (112 males and 109 females) have agreed and 27 (17 males and 10 females). On asking them to rate the community level of knowledge about breast cancer in KSA,238 have responded of whom 43 (25 males and 18 female), 92(32 males and 60 females) and 103(67 males and 36 females), have indicated, high, moderate and poor levels of knowledge, respectively, as shown in Figure 4.

On asking them to rate the role of ministry of health on community awareness about breast cancer in KSA,193 have responded of whom 79(34 males and 45 female), 98(49 males and 49 females) and 11(10 males and 6 females), have indicated, high, moderate and low levels of knowledge, respectively, as indicated in Figure 5.

On asking them about the best treatment for breast cancer, 250 have responded, of whom 54(38 males and 16 females), $9(7$ males and 2 females), 10 ( 7 males and 3 females), 74( 2 males and 72 females), $6(2$ males and 4 females), 6(2 males and 4 females), 91 (71 males and 20 females) have indicated Surgery, Radiotherapy, Chemotherapy, 
Biological, Alternative Medicine, Psychological, and All mentioned therapies, as indicated in Table $2 \&$ Figure 6.

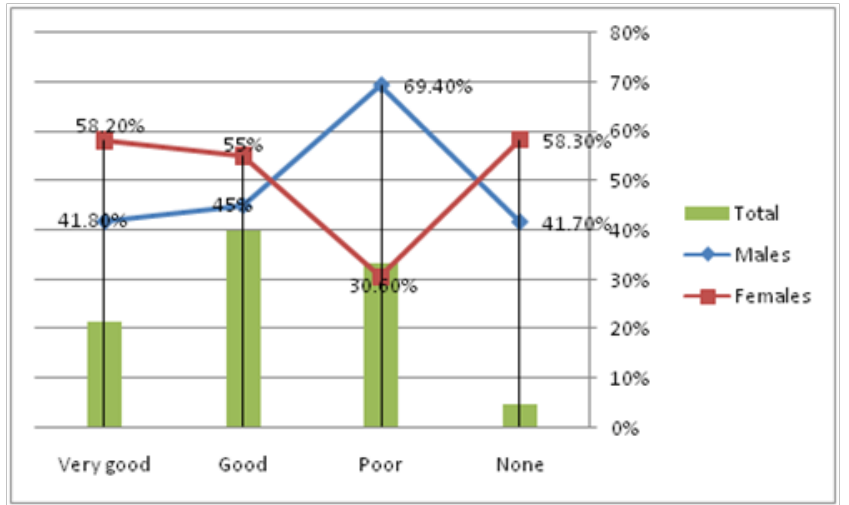

Figure I Description of study population by general knowledge about breast cancer.

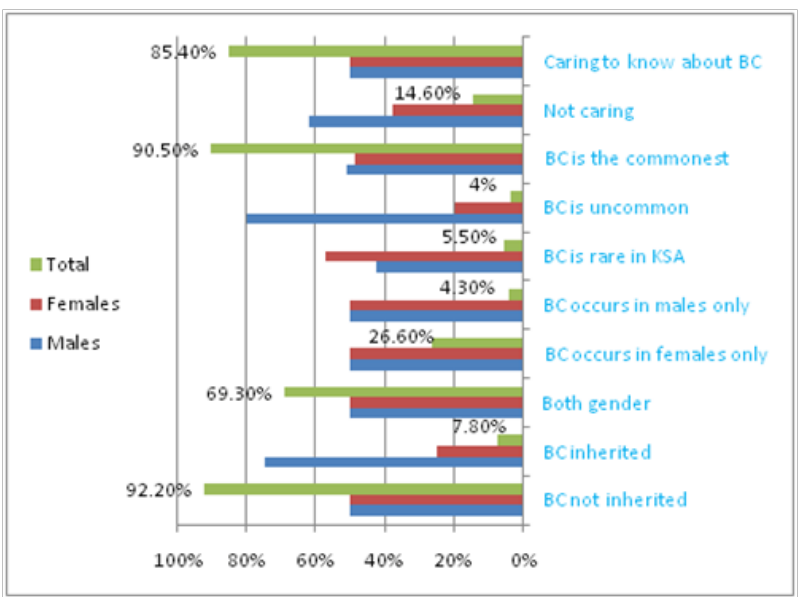

Figure 2 Description of study population by knowledge of breast cancer and its associated factors.

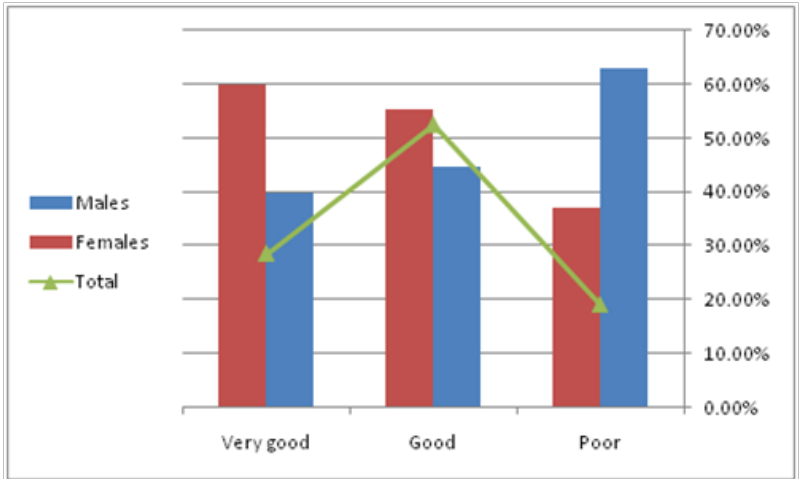

Figure 3 Description of study population by level of personal knowledge about BC.

\section{Discussion}

The present study aim at evaluating the levels of breast cancer related knowledge among Saudi medical students. This is a pilot study to explore relationship between common risk factors and breast cancer in Saudi population, in addition to evaluating the association between level of knowledge and stage of breast cancer diagnosis. Although several developing countries have implemented preventive drives to fight breast cancer with variable levels of success, but new breast cancer rates are still in elevation in many countries. The present study focused on the role of the medical students on the community education and awareness towards breast cancer and its associated cofactors and perception.

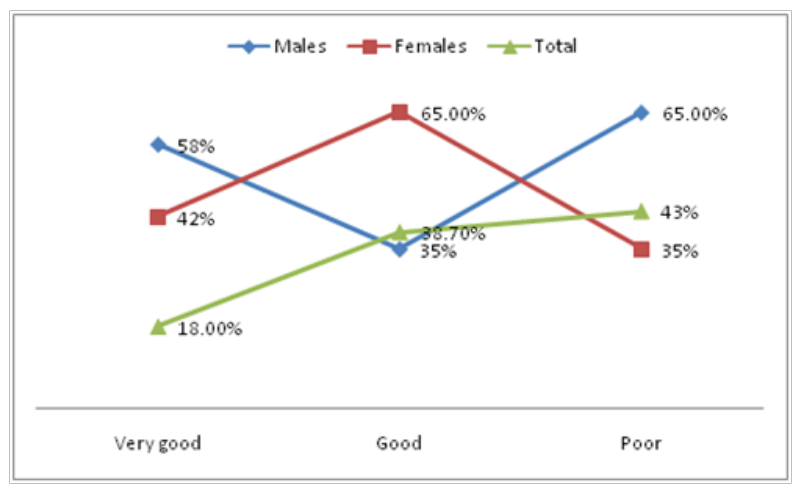

Figure 4 Description of study population by level of the community knowledge about $\mathrm{BC}$ in KSA.

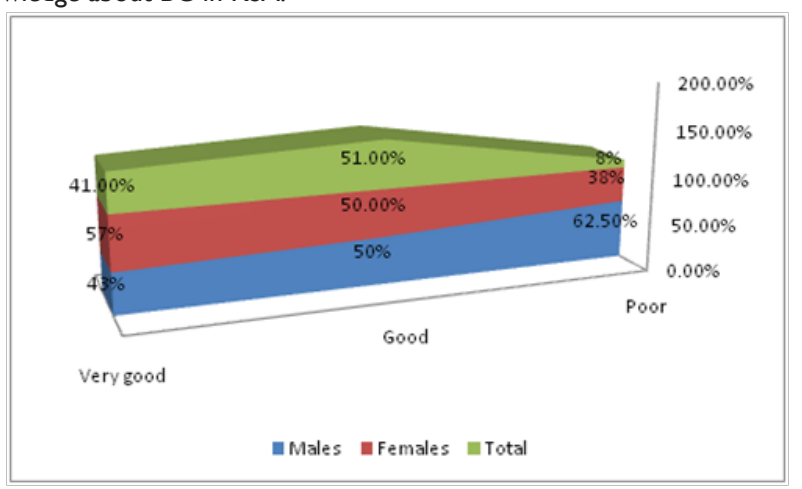

Figure 5 Description of study population by role of the Ministry of Health in community awareness about BC in KSA.

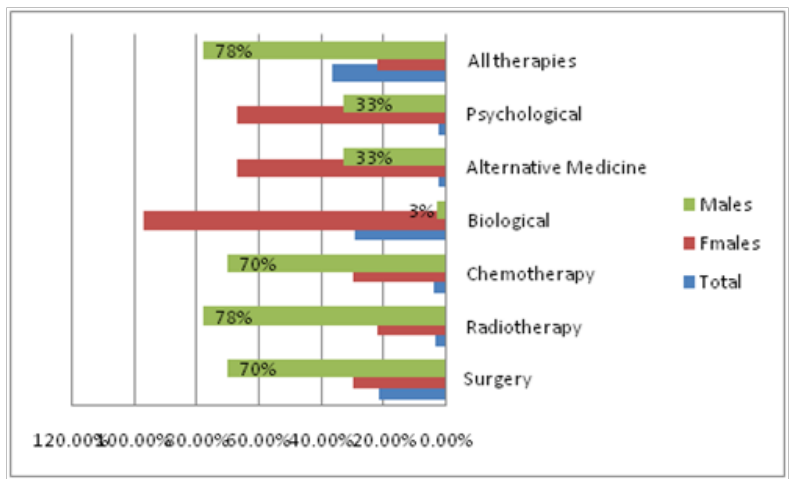

Figure 6 Description of study population by their knowledge about BC treatment.

However, the overall knowledge of the medical students was approximately $62 \%$ (very good and good). This relatively not high percentage for medical students' knowledge about breast cancer may predict low level of knowledge among general population. Although, there were similar studies from some of Saudi Arabia, but there is no such study from Hail region (Northern Saudi Arabia). In a study identify the effect of a Breast Cancer workshop on the knowledge and attitude of Saudi nursing students in relation to breast cancer and Breast Self-Examination (BSE). The data showed that the participants' knowledge of breast cancer increased significantly after the workshop. ${ }^{19}$ Another study assessed the levels of breast cancer 
awareness among Saudi females, and to compare between house wives and employee's women regarding knowledge and practical of breast cancer. The majority of participants showed good knowledge regarding risk factors of breast cancer (93.3\%), family history, contraceptive hormones, wearing tight bra, obesity, late menopause, and bearing the first child after age 30 years, $(75 \%, 71.7 \%, 63.7 \%, 55.3 \%, 43.7 \%$, $41.3 \%$, respectively). ${ }^{20}$ Luckily, most of the participants were eager to know more about breast cancer and the number of females is more than males. Strangely, about $26.4 \%$ believe that breast cancer affect females only, hence, $4.3 \%$ believe that breast cancer affect males only. These findings however, were not expected among medical students.

In the present study, also the knowledge in regard to the breast cancer inheritance was very low, only $7.9 \%$ believed that breast cancer can be inherited. Nevertheless, the majority of the variables assessed in this study showed relatively low measures in regard to the assessed value (medical students), which may be a predictor for the general population. Several studies have assessed the awareness levels among various Saudi sections, but most of these studies used variables other than the variables employed in the presence study.

In cross-sectional survey performed on male high school students across schools in Jeddah concluded that, knowledge of BC among male high school students in Saudi Arabia is still limited, and, therefore, programs and activities need to be established to increase awareness among high school students. ${ }^{21}$ Another study evaluated the level of breast cancer awareness and perceived barriers to seeking medical care among Saudi women, using internationally validated tool, emphasized the critical need for an effective national breast cancer education program to increase public awareness and early diagnosis. ${ }^{22}$ Another study to identify breast cancer knowledge, practice and screening barriers among women attending primary health centers (PHC) in Madinah, Saudi Arabia, concluded that the high levels of poor knowledge about cancer breast observed in this study reflect the need for greater efforts to increase breast awareness education. ${ }^{23}$ In other regions of Saudi Arabia; Al-Qassim it has been reported that the level of awareness of the females regarding breast cancer and BSE is not adequate and a health education program about breast cancer should be introduced in the region. ${ }^{24}$

However, various studies were conducted in this context almost all of them recall for implementing awareness strategies to increase the level of awareness among Saudi population. ${ }^{25-27}$ A significant number of women present with advanced stages of the disease due to lack of information, knowledge and awareness of early detection measures. Previous studies showed limited knowledge about breast cancer screening, and few women performed screening for early detection purposes. ${ }^{28-30}$ The limitations of this study were its cross sectional and pilot settings, as well as, the randomization in sample selection.

\section{Conclusion}

Saudi medical students' level of awareness of breast cancer is very low for several variables, which may be a predictor for the worse among general population. Implementing public awareness strategies are strongly needed in order to overwhelmed an ever-increasing burden of breast cancer among Saudi females.

\section{Acknowledgments}

Authors would like to express their special appreciation and thanks to Engineer Abdullah Ahmed Bugshan for funding this project. Authors appreciate the assistant from Medical Colleges at university of Hail. Especial thanks go to those who participated in this survey.

\section{Funding}

This work was supported by grants from Engineer Abdullah Ahmed Bugshan Chair for Breast Cancer Research.

\section{Conflicts of interest}

Authors declare there are no conflicts of interest.

\section{References}

1. Xiaomei Ma, Herbert Yu. Global Burden of Cancer. Yale J Biol Med. 2006;79(3-4):85-94.

2. International Agency for Research on Cancer. Breast cancer statistics; 2008.

3. Ahmed HG, Ali AS, Almobarak AO. Utility of Fine-Needle Aspiration As a Diagnostic Technique in Breast Lumps. Diagnostic Cytopathology. 2009;37(12):881-884.

4. Schwartsmann G. Breast cancer in South America: Challenges to improve early detection and medical management of a public health problem. J Clin Oncol. 2001;19(18 Suppl):118-124.

5. Shalini Saggu, Hasibur Rehman, Zahid K Abbas, et al. Recent incidence and descriptive epidemiological survey of breast cancer in Saudi Arabia. Saudi Med J. 2015;36(10):1176-1180.

6. Radi SM. Breast Cancer awareness among Saudi females in Jeddah. Asian Pac J Cancer Prev. 2013;14(7):4307-4312.

7. Al-Saad S, Al-Shinnawi H, Mahmood Shamsi N. Risk Factors of Breast Cancer in Bahrain. Bahrain Medical Bulletin. 2009;31:1-11.

8. Miller AB. Screening for breast cancer in the Eastern Mediterranean Region. East Mediterr Health J. 2010;16:1022-1024.

9. Brown R, Kerr K, Haoudi A, et al. Tackling cancer burden in the Middle East: Qatar as an example. Lancet Oncol. 2012;13(11):e501-e508.

10. Othman A, Ahram M, Al-Tarawneh MR, et al. Knowledge, attitudes and practices of breast cancer screening among women in Jordan. Health Care Women Int. 2015;36:578-592.

11. Ibrahim EM, Zeeneldin AA, Sadiq BB, et al. The present and the future of breast cancer burden in the Kingdom of Saudi Arabia. Med Oncol. 2008;25(4):387-393.

12. Rosner B, Colditz GA, Willett WC. Reproductive risk factors in a prospective study of breast cancer: the Nurses' Health Study. Am J Epidemiol. 1994;139(8):819-835.

13. Lipworth L. Epidemiology of breast cancer. Eur $J$ Cancer Prev. 1995;4(1):7-30.

14. Dumitrescu RG, Cotarla I. Understanding breast cancer risk - where do we stand in 2005? J Cell Mol Med. 2005;9(1):208-221.

15. Thompson D, Easton D. The genetic epidemiology of breast cancer genes. J Mammary Gland Biol Neoplasia. 2004;9(3):221-236.

16. Jemal A, Bray F, Center MM, et al. Global cancer statistics. CA Cancer J Clin. 2011;61(2):69-90.

17. Dumitrescu RG, Cotarla I. Understanding breast cancer risk - where do we stand in 2005? J Cell Mol Med. 2005;9(1):208-221.

18. Naser Elkum, Taher Al-Tweigeri, Dahish Ajarim, et al. Obesity is a significant risk factor for breast cancer in Arab women. BMC Cancer. 2014; $14: 788$.

19. Yousuf SA. Breast Cancer Awareness among Saudi Nursing Students. JKAU: Med Sci. 2010;17(3):67-78.

20. Mohammed R, Mansour MAM, Dorgham LSH. Breast Cancer Awareness among Saudi Females in Taif, Saudi Arabia. International Journal of Science and Research. 2014;3(11):439-45. 
21. Al-Amoudi S, AlHomied MT, AlSayegh NY, et al. Breast Cancer Knowledge Among Male High School Students in Saudi Arabia. J Cancer Educ. 2016;31(4):784-788.

22. A1-Khamis NK. Low Awareness of Breast Cancer and Considerable Barriers to Early Presentation Among Saudi Women at a Primary Care Setting. J Cancer Educ. 2016.

23. Al-Zalabani AH, Alharbi KD, Fallatah NI, et al. Breast Cancer Knowledge and Screening Practice and Barriers Among Women in Madinah, Saudi Arabia. J Cancer Educ. 2016.

24. Jahan S, Al-Saigul M, Abdelgadir H. Breast cancer: Knowledge, attitudes and practices of breast self-examination among women in Qassim region of Saudi Arabia. Saudi Med J . 2006;27(11):1737-1741.

25. Madkhali NA, Santin O, Noble H, et al. Understanding breast health awareness in an Arabic culture: qualitative study protocol. J Adv Nurs. 2016;72(9):2226-2237.
26. Abolfotouh MA, BaniMustafa AA, Mahfouz AA, et al. Using the health belief model to predict breast self-examination among Saudi women. BMC Public Health. 2015;15:1163.

27. Almutairi KM, Ahmad M, Vinluan JM, et al. Random Cross-Sectional Determination of the Level of Awareness Among Female Saudi Patients About Breast Cancer. J Cancer Educ. 2016;31(1):131-135.

28. Othman A, Ahram M, Al-Tarawneh MR, et al. Knowledge, Attitudes and Practices of Breast Cancer Screening Among Women in Jordan. Health Care Women Int. 2015;36(5):578-592.

29. Arevian M, Noureddine S, Abboud S. Beliefs related to breast cancer and breast cancer screening among Lebanese Armenian Women. Health Care Women Int. 2011;32(11):972-989.

30. Mahfouz AA, Hassanein MH, Nahar S, et al. Breast cancer knowledge and related behaviors among women in Abha city, southwestern Saudi Arabia. J Cancer Educ. 2013;28(3):516-520. 